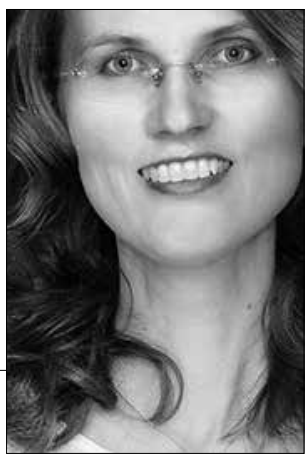

\title{
JEAN-MARIE GUYAU MENO TEORIJŲ RECEPCIJA XX A. PRADŽIOS LIETUVIŲ SPAUDOJE. SOFIJOS ČIURLIONIENĖS- KYMANTAITĖS ATVEJIS
}

\author{
The Reception of Art Theories by Jean-Marie Guyau
} in Lithuanian Press in the Beginning of the 20th Century. The Case of Sofija Čiurlionienè-Kymantaite

\section{SUMMARY}

The article reviews the reception of aesthetic ideas of Jean-Marie Guyau (1854-1888) in the Lithuanian press at the beginning of the 20th century. Guyau's ideas of the sociological role of art were well known in the East-Central Europe at the end of the 19th century. The first one to reflect on Guyau's "Art from a Sociological Point of View" (,L'art au point de vue sociologique", 1889) in public discourse was Sofija Čiurlionienè-Kymantaitè, one of the most prominent "modern romanticists" in ethnical Lithuanian culture. Her statements in "The Meaning of Art in the Life" (1913) are examined here in comparison with the French thinker's ideas. A few years later Guyau was quoted by Ignas Jurkūnas (Ignas Šeinius, 1889-1959), a representative of the next generation, that are referred to as "romantic modernists". Finally, in a more systematic manner, Vincas Mykolaitis-Putinas (1893-1967) in 1920-1922 reflected on Guyau's "Contemporary Aesthetic Problems“ („Les problemes de l'Esthetique contemporaine."

\section{SANTRAUKA}

Straipsnis skirtas modernių teorijų recepcijai XX a. pradžios lietuvių kultūroje. Jame daugiausia dėmesio skiriama XIX a. antroje pusėje populiaraus prancūzų filosofo Jeano-Marie Guyau (1854-1888) socialinėms ir estetinėms idėjoms, kurios lietuvių spaudoje imtos reflektuoti tik XX a. antrajame dešimtmetyje. J.-M. Guyau knygos Menas sociologiniu požiūriu (L'art au point de vue sociologique, 1889) idèjas pirmoji į viešąji diskursą 
įtraukè viena lietuvių ankstyvojo modernizmo pradininkių Sofija Čiurlionienė-Kymantaitė. Šiame tyrime detaliau aptariama, kuriuos S. Čiurlionienės-Kymantaitės teiginius inspiravo minėtoji J.-M. Guyau studija. Teigiama, kad J.-M. Guyau estetinis vitalizmas suteikè impulsų įtvirtinant romantinį menininko - visuomenès vedlio - statusą XX a. pr. lietuvių kultūroje. Epizodiškai J.-M. Guyau idèjas 1915 m. nušvietė Ignas Šeinius (Ignas Jurkūnas), sistemingiau jo estetinėmis pažiūromis 1920-1922 m. rėmėsi Vincas Mykolaitis-Putinas.

Straipsnyje "Dailès prasmè gyvenime“ S. Čiurlionienè-Kymantaitè palietė turinio, formos ir medžiagos santykio klausima, teigdama, kad lietuviu grynojo meno pastangas dar varžo techninio meistriškumo (formos) stoka. Sumanymai kartais didingi, bet, neigaudami meno kūrinio pavidalo, jie nepaveikūs. Ir priešingai - net kuklus lyrinis turinys, išreikštas profesionalia plastine kalba, veikia suvokèjo vaizduotę. Tačiau kad ir kokie svarbūs formos dalykai, jie negali dominuoti turinio sąskaita. Prie turinio, formos ir medžiagos tapusavio sandermès S. Čiurlionienè pridūrè esminį komponentą - „kūrẻjo individualizmą”, apimantị ir jo skonio pajauta, ir îspūdžio bei perteikimo subjektyvumą: mat nèra jokio daikto, duoto objektyviai, jo percepcija nuolat kinta dèl pačios sielos dinamiškumo, judrumo. „Taigi prie turinio kokybės prisideda dar vidujinè kokybè ir dailininko skonis", - apibendrino autore ${ }^{31}$.

„Dailès prasmè gyvenime" autorè palaiko romantizmo tradicijos itvirtintą ¡kvėpimo koncepciją: menininko fizinis kūnas visa savo energija paklūsta tam tikslui, prie kurio veda įkvejpimas. Kūrybos procesas susijęs su „šventumo“ išgyvenimu, ir kūrinio ịkūnijimas medžiagoje yra lydimas didelio džiaugsmo, nepaisant skaudžių psichologinių aplinkybiư kuriomis kūrinio idèja užsimezgè: „Nors giliausia nelaimè ikvejptų dailininko veikalo mintí, jis visados, paversdamas ją kūnu, ragauja neapsakomo džiaugsmo.
Kodèl? Nes žmogus myli savo stiprybę ir myli be galo savo galybės pajautimą." ${ }^{32}$ Taip permąstoma J.-M. Guyau mintis (,tas tai noras yra paties gyvenimo apsireiškimas - gyvumo-gyvybės, tai ir yra žmogaus stiprybės išsiliejąs džiaugsmas"33). Per amžius kuriamas menas ugdo vèliau gyvenančiu asmenybiu subtilumą - „žmogus besiplètodamas jautrejja ir švelnëja visais atžvilgiais. <...> Kumšti užstoja žodis, žodi žvelgesys, o ateina laikas, kada ir žvelgesys yra jau labai realinis apsireiškimas, atsiranda dar švelnesnẻ ir tylesnė žmogaus su žmogumi kalba - sielu susitinkantieji spinduliai" ${ }^{34}$. Straipsnio autore aptaria jai svarbią intuicijos temą. Kaip ryškiausią tokio fenomeno, kai „[s]ielos kalbasi tarp savęs lengvais kaip šešèliai, pajautimų nepagaunamais žodžiais" ${ }^{35}$, vaizduotoją pamini Maurice'ą Maeterlincka, perteikia jo pjesès „Neregiai“ esmę, darydama apibendrinimą: „Ar ne tokie neregiai mes visi čia gyvename, kuomet balso vidaus vedami, bijome jo klausyti ir išsigandę, neramūs ieškome to matomame pasaulyje, kas mums patvirtintų mūsų tiesą ir jokio patvirtinimo rasti negalime? Žinoma, kaip „sveiki galvočiai” vadina tokius daiktus nervu liga, prasimanymais. ${ }^{\text {"36 }}$ Šias pastabas formuluoja ji pati.

Straipsnyje pabrěžiamas antimimetinis meno aspektas: tikra meninè kūryba liudija niekuo neapribotą, nesuvaržytą turinio laisvę. Laikomasi J.-M. Guyau požiūrio, kad sekantis gyvenimu, imituo- 
jantis gamtą menas pralaimi jiems, tarsi fotografijoje sustingdo tai, kas yra nuolatos dinamiška ir nepakartojamai pilnatviška. Menas perteikia objekto atspindi sieloje, tad „gyvenimas yra tik žalia medžiaga, dailè gi yra jo sintezè, tvarkoma asmens teisèmis. Juo labiau šitoji sintezè yra negirdèto ir neregèto apsireiškimu, juo aukštesnè dailè" ${ }^{37}$. J.-M. Guyau teigè, kad menas ne analize gaudo gyvenimo elementus, o pranoksta tikrovę ir išauga viršum jos, ir ,jo rezultatas yra sintezè, kuria siekiama sukurti naują tikrovę dvasiai, iš naujo performuoti pasaulio fragmentą"38.

S. Čiurlionienè-Kymantaitè, remdamasi J.-M. Guyau, pateikè meną kuriančiųjų hierarchiją: grynojo meno kūrèjais gali būti genijai ir talentai. Genijai - retai iškylantys dideli novatoriai, o talentai gražiai, giliai, savitai pakartoja "tą pačią jau tartą mintį" (jie daug gali formos dalykuose). Trečiąją grupę sudarantys didesnių ar mažesnių gabumų žmonès pakartoja, kas jau buvo pasiekta tiek turinio, tiek formos požiūriu, iš savo darbo siekia pragyventi, todèl kuria „dar ne meną“39 (taikosi ì pirkejjo skoni, meną supranta kaip prekę). Atitinkamai piramidès principu autorè aptarè ir suvokèjų kategorijas. Populiariausias esąs utilitarinis meno supratimas: estetizuoti žmogaus aplinka, drabužius, teikti patogumo, linksminti (ypač tai būdinga muzikos, šokio žanrams). Rafinuočiau suvokiantieji meną vadovaujasi skoniais, tikisi iš jo "tokios pat emocijos ir susijaudinimo, kaip iš gyvenimo". Tačiau tikèdamiesi iš meno kūrinio ,gyvenimo tikrumo", dèl kurio verkiama, juokiamasi, geidžiama, suvokejjai nesupranta, kad tai nèra galutinis meno tikslas, nors geras kūrinys visada sukelia ir emocijas ${ }^{40}$. Tad toks meno supratimas dar vis yra taikomasis ir siejamas su pramoga, „mados vejjais". Šią sritị dar gali užpildyti mažesnių ar didesnių gabumų žmonių veikla (anot J.-M. Guyau, tai tik seki$\mathrm{mai}^{41}$ ), jai taip pat priskiriamas kinematografas, farsai. Piramidès viršūnèje - tikrasis, arba grynasis, menas, jis nesitapatina su gyvenimu, tikras menininkas maištauja prieš minios skonį. Jo kūrëjai negalvoja, koki ispūdi padarys, jiems „,tai yra šventa, brangi prievarta, sunkus darbas, be kurio gyvuot visai negalima, tai yra jų sielos žiedas, i kuri icdètos visos pajėgos, visos sultys..." ${ }^{42}$ Genialus menas paprastai ivvertinamas vèlesnių epochų, nes pranoksta savo meto pasaulèvoka, užgriebia kažką modernaus, iš ateities (todèl Williamo Shakespeare'o charakteriai i̇domūs dabartiniam psichologui). J.-M. Guyau juos lygina su galingomis planetomis, kurios apie save sukuria sistemą ${ }^{43}$. Genijus suvokia tą savo pasiuntinystę i ateitį: „Ne jums tai darau, ne aš pas jumis, bet bus laikas, kad jūs pas mane ateisite." Ir ne syki laukia to atejimo... kelis šimtus metų" ${ }^{\prime 4}$. Jo vienišumas tragiškas. S. Čiurlionienè-Kymantaite pabrèžè svarbiausią tikram menininkui „kūrinio gimimo valandą“, o ne jo tolesnes realizacijas visuomenèje.

Šio klausimo išsamesnis apmąstymas, kaip ir viso straipsnio užmojis, galejo kilti iš prisimintų pokalbių su Mikalojumi Konstantinu Čiurlioniu, kurio, regis, neaplenkè ir Johno Ruskino (1819-1900) utopinès idejos apie tai, kad socialinius pokyčius visuomenèje užtikrins grožio itvirtinimas jos gyvenimo kasdienybejje. 
Šiame sumanyme dailininkui suteikta visuomenès perkūrëjo misija ${ }^{45}$. Pasak Jadvygos Čiurlionytės, jos brolis buvo į savo biblioteką parsivežęs Roberto de la Sizeranne'o knygą Ruskinas ir grožio kultas ${ }^{46}$ (Ruskin i kult piękna, 1900, vert. iš pranc. Ruskin et la religion de la beauté, 1866), šios knygos pabaigoje išsakomas autoriaus tikëjimas, kad pasigèrejimas, kaip aukščiausia estetinio gyvenimo pakopa, ivveiks blogi ${ }^{47}$. Tad straipsnyje „Dailès prasmè gyvenime" plètojama visuomenès dvasinès pažangos, kai menininkas atlieka esmini vaidmenį, idejja. J.-M. Guyau nuostatos sustiprino vizija, kad dèl meno ateitis bus morali. Straipsni parašyti galejjo paskatinti ir M. K. Čiurlionio kūrybinio palikimo apmąstymai: Sergejaus Makovskio publikacijos 1912 m. „Apolone", Boriso Lemano knyga Čiurlionis, tais pačiais metais St. Peterburge surengtos pomirtinès jo paveikslu parodos ir koncertas, $1913 \mathrm{~m}$. Vilniuje atidarytos nuolatinès menininko darbu parodos ${ }^{48}$ (straipsnis paskelbtas tais pačiais metais).

Rinkinyje Lietuvoje iškèlusi klausima, kam reikalinga meno kritika, jei dideli ir stiprūs talentai patys žino, ko ju darbai verti, ir pradejusi dèstyti, kad tik vidutinių gabumų menininkams reikia patarimu, o genialiems tiesiog malonu sutikti nusimanantį žmogư ${ }^{49}$, S. ČiurlionienèKymantaitė pratęsė savo apmąstymus straipsnyje "Dailès prasmè gyvenime“. Nuovokus kritikas, aptardamas gerą kūryba, net negalvoja mokyti menininko. Lietuvos sąlygomis, kai spauda iš dalies atlieka dar neįsteigtu ugdymo institucijų vaidmení, kritikas gali būti tik suvokèjų ugdytojas (tai taip pat artima J. Ruskino idejoms). Tikimasi, kad jis supažindins visuomenę su tais meno pavyz- džiais, kurie visuotinai pripažinti šedevrais, tokiu būdu puoselèdamas jos skonį. J.-M. Guyau minties vedama S. Čiurlionienè-Kymantaitè teigè, kad menas - visos tautos nuosavybė, ir kartojo J. A. Herbačiausko, A. Varno bei A. V. Staneikos lietuvių spaudoje skelbtą minti, kad mene kaip veidrodyje tauta gali išvysti savo didžiuosius troškimus, save geriau pažinti.

Apibendrinant reiktų pabrèžti, kad S. Čiurlionienès-Kymantaitės straipsnyje daugeliu atvejų kūrybiškai taikytos J.-M. Guyau idejos. Nutylimos nepalankios prancūzų filosofo pastabos apie simbolistinio meno hermetiškumą. Nereflektuojamas ir J.-M. Guyau ideju prieštaringumas (pvz, kad genijus, iš principo elitine figūra, priešinga miniai, neinanti pakeliui su meno demokratinimo ideja, staiga padaromas jo veikaluose moraliniu vedliu). Straipsnis „Dailès prasmė gyvenime" tęsè visuomenès moralinès pažangos per grožio suvokimo ugdymą vizija, kuri M. K. Čiurlionį veikiausiai pasiekè pirmiausia studijuojant J. Ruskino idejjas. Ši straipsnị inspiruoti galëjo suaktyvèję M. K. Čiurlionio fenomeno apmąstymai. „Dailès prasmė gyvenime“ buvo paskutinis grynai meno klausimams skirtas S. Čiurlionienės-Kymantaitès straipsnis, kuriame mėginta koncentruotai aptarti meno kilmę, funcionavimą ir prasmę. Rašydama ši straipsni, ji dar planavo studijas Prancūzijoje, minèjo Sorbona, tad patencialiai galejo tapti ir kitų prancūzų filosofu idèjų taikytoja savajai kultūrai. Deja, galutinai šiuos planus sujaukè prasidejęs Pirmasis pasaulinis karas.

S. Čiurlionienès-Kymantaitès estetinius autoritetus perèmė jaunesnès kartos, Aušros Jurgutienés vadinamos „ro- 
mantiškais modernistais" prieš išleidžiant almanachą Pirmasai baras, kuriame savo tekstus skelbẻ Stasys Šilingas, Balys Sruoga, pati S. Čiurlionienè ir kt., šio leidinio reikšmingas grupès bendradarbis Ignas Jurkūnas (Šeinius), išvertęs almanachui pirmą lietuvių spaudoje didesni F. Nietzsche's Štai taip Zaratustra kalbejjo fragmentų rinkinį ${ }^{51}$, Šeniavskio universitete Maskvoje studijavęs meno filosofija, skaite $1915 \mathrm{~m}$. sausio pabaigoje Vilniaus inteligentu klube paskaitą „Meno problemos“, kurios vieną dali sudarè meno teorijų apžvalga („Vilties“ korespondentas nurodè, jog tai ištraukos iš rašomo to paties pavadinimo veikalo) ${ }^{52}$. Paskaitoje, greta kitų autoritetų, prelegentas rèmėsi ir J.-M. Guyau idejjomis, tačiau ne sistemingai, o fragmentiškai. Tarp svarbiausių I. Jurkūno teiginių - galimybė per meno kūrybą spręsti metafizinio ilgesio, nemirtingumo klausimą. Dažnai vartota „meno šventovės“ sąvoka, meno misija sureliginta, teigta, kad menas - vienintelè „sielos kūrybos" sritis, kviesta eiti šiuo keliu meno autonomijos šalininkus; stengtasi apibūdinti nepaaiškinamą jo kilmę (meno ištakos - „pasąmonès gelmėse"), méginta atsiriboti nuo estetiniu sensualizmo teoriju, bet akcentuota, kad menas išreiškia jausmus. Paskaitos teiginiai paskatino diskutuoti konservatyvujji Adomą Jakštą ${ }^{53}$.

Kitas „romantiško modernizmo" kartos atstovas, Vincas Mykolaitis-Putinas, 1920 m. rengdamas referatą "Grožio ir meno kuriamosios dailès reikšmė" ateitininkų 10-ies metų sukaktuvių kongresui ir praplèsdamas savo dèstymą to paties pavadinimo straipsnyje (1921-1922), pa- sirèmè ankstesniu nei Menas sociologijos požiūriu J.-M. Guyau veikalu - Šiuolaikinès estetikos problemos (Les problèmes de l'esthétique contemporaine, Paris, 1913; pirmąkart paskelbta $1884 \mathrm{~m}$. $)^{54}$. V. MykolaitisPutinas pabrèžè J.-M. Guyau minti, kad groži asmuo suvokia visa savo esybe, kuri apima jausmus, valią ir protą. Jis apibendrino, kad visų „,sielos galių sintezę" sužadina tik genialaus meno kūrinio grožis. Dar sykị svarstydamas klausimą, kokia meno reikšmè gyvenime, V. Mykolaitis-Putinas, kaip ir J.-M. Guyau, iškèlè meno moralumo klausimą, aksiologiškai šalia grožio akcentuodamas ir gèrį. Prancūzų filosofo idejjų veikiamas, straipsnio autorius tvirtino, kad „mokslas, religija ir dora" nepadaro tokio poveikio žmonėms kaip menas ugdydamas žmonių sielas per jausmus. „Čia tirpsta luomų ir partiju priešingybès. Grožis menas ir dailè supa visuomenę bendros simpatijos vainiku. ${ }^{\text {"55 }}$ Mat per ekstazę žmogus groži suvokia reliatyviai aukščiausiu laipsniu. Ši patirtis suartina meno ir religijos misiją. Pripažindamas, kad mistinè ekstazė gali būti giliausia, savo dèstymą V. MykolaitisPutinas grindè Viačeslavo Ivanovo, su kuriuo 1912 m. susipažino S. Čiurlionienè, teurgijos samprata ${ }^{56}$. Atmesdamas sensizmo, utilitarizmo ir estetizmo pažiūras, straipsnio autorius nuosekliau nei S. Čiurlionienè-Kymantaitè rinko kontrargumentus „menas menui“ koncepcijai. Pagrindiniai argumentai - kad joks reiškinys negali būti sau tikslas, kad per intuiciją siekiantis grožio idejjos "laisvas" menininkas, atitrūkęs nuo grožio šaltinio - Absoliuto, tos idejjos išreikšti nepajègia. J. M. Guyau gyvenimo apstybès sampratą V. Mykolaitis-Putinas susiejo 
su Amžinojo Gyvenimo sąvoka, šios metafizinès tikrovės siekiamybe. Grįždamas prie J.-M. Guyau meno apibrěžimo (kad tai ,„ikūnyta grožio idèja“) ${ }^{57}$ ir pabrèždamas, kad vertingas tik toks menas, kuris gaivalingai veržiasi ,iš tyros menininko sielos“, V. Mykolaitis-Putinas formulavo vizija, kad menininko „kūriniai grožio šydu nedangstys bedugnių, bet didingais viadukais tiesis nuo viršūnès i̇ viršūnę, vesdami vis aukščiau ir aukščiau i pati grožio sostą “58. Šia vizija autorius grindè ir simbolistinio meno sampratą - tai menas, kuris, pasitelkdamas šio gyvenimo vaizdinius, kalba apie tikrają realybę ir savo didumu veikia visuomenę. Nuo visuomenès apibrèžimų jis perèjo prie tautos sąvokos aptarimo ir kèlè tautos, kaip kolektyvinio individo, meno reikšmès klausimus. Rašydamas, kad „[m]enininkas, šaknimis įsièmęs i savo tautos dvasia, gamina jai žiedų iš jos pačios syvų", kad genialūs menininkai nurodo tautai jos ateities kelia yra "tautiniai pranašai“59, V. Mykolaitis-Putinas pakartojo S. Čiurlionienès-Kymantaitès straipsnyje „Dailès prasmè gyvenime" akcentuotus dalykus. Sutinkant su Vandos Zaborskaitès teiginiu, kad J.-M. Guyau pažiūros „giliausiai atsispindi V. Mykolaičio-Putino estetikoje ${ }^{\prime 60}$, verta būtų patikslinti, kad prancūzų mąstytojo pažiūras reflektavusi S. Čiurlionienè-Kymantaitė daugumą akcentų išdėstė aštuoneriais metais anksčiau. Abiems autoriams buvo artimos grožio metaforos, primenančios Friedricho Schillerio pateiktas Laiškuose apie estetini ugdyma, bet, kitaip nei S. Čiurlionienė, V. Mykolaitis-Putinas, pagrisdamas savo simbolizmo samprata, meno teorijoms siekè grąžinti teologinès metafizikos aši ${ }^{61}$. J.-M. Guyau estetinio vitalizmo idejomis esmingiau pasirèmę S. Čiurlionienè-Kymantaitè ir V. Mykolaitis-Putinas buvo tos pačios meninès tradicijos (neoromantizmo, mistinio simbolizmo), tik skirtingų kartų, puoselètojai, skaidriojo meno, kurio skleidžiama pagrindinė žinia neprieštarautų gèrio ir tiesos idejaia ${ }^{62}$, šalininkai. Reikètų pridurti, kad 1922 m. apsigynęs Friburgo universitete filosofijos daktaro disertaciją iš Vladimiro Solvjovo estetikos ir nuo kitu metu pradèjęs dèstyti Lietuvos universitete tarp kitų disciplinu ir estetikos istorija, V. Mykolaitis-Putinas turèjo auditorija, o S. Čiurlionienè, nuo 1925 m. tame pačiame universitete dèsčiusi lietuvių kalba, jau nebegalèjo profesiškai konkuruoti su jaunesnès kartos estetikais.

\section{IŠVADOS}

Apibendrindami straipsnyje apžvelgtus recepcijos atvejus, galime teigti, kad J.-M. Guyau meno socialumo teorijos lietuvių visuomenę pasiekè vèluodamos keliais dešimtmečiais - dèl 1964-1904 m. carinès Rusijos vykdytos politikos Lietuvoje (universiteto uždarymo, spaudos lotyniškais rašmenimis draudimo) vèla- vo instituciju, per kurias sklistų estetinės idejos, steigimas. Su J.-M. Guyau knygomis supažindinę lietuvių visuomenę autoriai studijavo Šveicarijos, Lenkijos, Rusijos kultūros centruose. XIX-XX a. sandūroje buvusios labai populiarios, per kelis dešimtmečius Europoje jos prarado aktualumą. Nuo 1923 m. Lie- 
tuvos universitete pradejęs dirbti Vosylis Sezemanas savo estetikos paskaitose J.-M. Guyau darbų praktiškai nebeminejo: Estetikoje jis ivvardytas tik karta, kalbant apie subjektyvistinių suvokimo teorijų šalininkus. Ketvirtajame dešimtmetyje José Ortega y Gassetas rašè, kad iš J.-M. Guyau knygos Menas sociologiniu požiūriu išliko tik pavadinimas, o pati knyga turi būti dar parašyta - mat reikia susitelkti $\mathfrak{i}$ esmingiausius ir slapčiausius dalykus, o J.-M. Guyau dèl trumpo savo gyvenimo esą aptarè pa-

\section{Literatūra ir nuorodos}

31 Sofija Čiurlionienè-Kymantaitè, p. 196.

32 Ten pat, p. 193.

33 Ten pat.

34 Ten pat, p. 200.

35 Ten pat, p. 199.

36 Ten pat, p. 200.

37 Ten pat, p. 201.

38 J.-M. Guyau, p. 58.

39 Sofija Čiurlionienè-Kymantaitè, p. 203.

40 Ten pat, p. 202.

41 J.-M. Guyau, p. 81.

42 Sofija Čiurlionienè-Kymantaitè, p. 202.

43 J.-M. Guyau, p. 82.

44 Sofija Čiurlionienè-Kymantaitè, 202.

45 Anot J. Ruskino, meną tik tada įmanu atnaujinti, kai atnaujinama visuomenè (Algirdas Gaižutis, Meno sociologija. Vilnius: Enciklopedija, 1998, p. 34).

46 Jadvyga Čiurlionytè, Atsiminimai apie M. K. Čiurlioni. Vilnius: Vaga, 1970, p. 202.

47 R. de la Sizeranne, Ruskin i kult piękna. Z francuskiego przełożył A. Potocki. Lwów-Warszawa, 1900, t. 2, s. 154 (Radosław Okulicz-Kozaryn, Wilno w powijakach. M. K. Čiurlionisa plan podźwignięcia kulturalnego Litewskiej stolicy. Mikalojus, Konstantinas Čiurlionis Vilniuje. Vilnius: Lietuvių literatūros ir tautosakos institutas, 2016, p. 40).

48 Liunas, M. K. Čiurlionies parodą atidarant. Lietuvos žinios, 1913 spalio 24 (lapkričio 6), Nr. 126, p. 2-3.

49 Sofija Čiurlionienè-Kymantaitè, p. 144. viršutiniškus ir trivialius socialumo aspektus $^{63}$. Tačiau kadangi XX a. pr. lietuvių kultūroje meno vertingumas tebebuvo siejamas su jo ugdomuoju vaidmeniu visuomeneje, J.-M. Guyau estetinio vitalizmo idejjos pasirode parankios steigiant menininko socialini reikšmingumą naujai besiformuojančios tautinès inteligentijos gyvenime ir puoselejant kalokagatijos ideala, kuris didžiajai suvokeju daliai, išskyrus XX a. trečiajame dešimtmetyje iškilusių avangardistų auditorija, išliko aktualus.

50 Aušra Jurgutienė, p. 22. (S. Čiurlionienè-Kymantaitè su J. A. Herbačiausku, Vydūnu, Vincu Krève, Liudu Gira, Juozu Tumu-Vaižgantu, Šatrijos Ragana, Motiejumi Gustaičiu priskirta prie moderniųjų romantikų. Tarp romantiškojo modernizmo atstovų - B. Sruoga, I. Šeinius, V. Mykolaitis-Putinas, Faustas Kirša, Julijonas LindeDobilas.)

51 Fridrichas Nicšè, Šitaip kalba Zaratustra. Iš vokiečių k. vertė I. Šeinius. Pirmasai baras. Vilnius, Martino Kuktos spaustuvè, 1915, p. 151. Tarp F. Nietzsche's idèjų perteikèjų svarbu paminèti ne tik J. A. Herbačiauską (Juozapas Albinas Herbačiauskas, Erškěčiu vainika. Vilnius: Vaga, 1992, p. 66, 75-76; Juozapas Gerbačiauskis, Gerbiamoji redakcija. Aušrinè, 1911, Nr. 2 (9), p. 60; Rūta Marija Vabalaitè, Friedricho Nietzsche'ès filosofijos recepcija ikikarineje Lietuvoje. LogosVilnius 75, 2013, p. 6-12), bet ir šio veikalo 1906 m. leidimą lenkų kalba skaičiusi M. K. Čiurlionį. Apie šio menininko sąsajas su F. Nietzsche's gyvenimo filosofija turbūt pirmoji aiškiau užsiminė A. Jurgutienė (Aušra Jurgutienė, p. 196).

52 Vilniaus kronika. Viltis, 1915, sausio 13 (26), Nr. 9, p. 3. (Žinia apie paskaitos nukèlimą: Vilniaus kronika. Viltis, 1915, sausio 18 (31), Nr. 14, p. 2.)

53 Adomas Jakštas, Raštai. T. 3: Estetika. Vilnius: Mintis, 1997, p. 42 (pirmą kartą publikuota: A. J. J. Jurkūno paskaita apie meno problemas. Viltis, 1915, sausio 31 (vasario 13), Nr. 25, p. 1-2). I. Šeiniaus rašytame Pirmajam barui (1915) straipsnyje „Duonelaitis” modernusis menas 
apibūdinamas kaip individualus dvasios kūrinys, atsirandantis vadovaujant kūrèjo jausmui, intuicijai.

54 Straipsnis skelbtas žurnale Logos, 1921-1922, kn. 1, sąs. 1-2, p. 49-63.

55 Vincas Mykolaitis-Putinas, Grožio ir meno kuriamosios dailès reikšmè. Raštai. T. 8: Estetika. Literatūros etiudai. Vilnius: Vaga, 1999, p. 95.

56 V. Mykolaitis-Putinas remėsi V. Ivanovo knyga Vagos ir ežios (Борозды и межи, 1916). V. Ivanovas 1912 m. Peterburge, dovanodamas S. Čiurlionienei savo knygą Po žvaigždes, ịrašè jai dedikaciją.

57 Vincas Mykolaitis-Putinas, p. 110.
58 Ten pat, p. 108-109.

${ }^{59}$ Ten pat, p. 96.

60 Ten pat, p. 444.

${ }^{61} \mathrm{Plg}$. A. Jakšto diskusiją su V. Čepinskio dèstymu (Adomas Jakštas, Raštai. T. 1: Mokslas, filosofija, religija. Vilnius: Mintis, 1995, p. 259-270).

62 V. Ivanovo dovanotoje S. Čiurlionienei knygoje pabraukti šie žodžai: «Ибо скрытое начало добра - то же, что начало красоты; имя ему нисхождение» (В. Иванов, По звездам. Статьи и афоризмы. С. Пб.: Оры, 1909, с. 32).

63 José Ortega y Gassetas, Mūsu laiku tema ir kitos esè. Vilnius, ALK, Vaga, 1999, p. 472. 